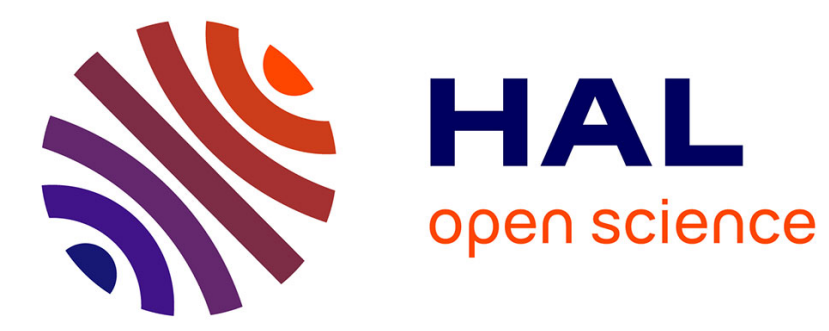

\title{
Radon reduction and radon monitoring in the NEMO experiment
}

\author{
A. Nachab
}

\section{To cite this version:}

A. Nachab. Radon reduction and radon monitoring in the NEMO experiment. 2nd Topical workshop in Low Radioactivity Techniques "LRT 2006", Oct 2006, Aussois, France. in2p3-00128409

\section{HAL Id: in2p3-00128409 https://hal.in2p3.fr/in2p3-00128409}

Submitted on 1 Feb 2007

HAL is a multi-disciplinary open access archive for the deposit and dissemination of scientific research documents, whether they are published or not. The documents may come from teaching and research institutions in France or abroad, or from public or private research centers.
L'archive ouverte pluridisciplinaire HAL, est destinée au dépôt et à la diffusion de documents scientifiques de niveau recherche, publiés ou non, émanant des établissements d'enseignement et de recherche français ou étrangers, des laboratoires publics ou privés. 


\title{
Radon reduction and radon monitoring in the NEMO experiment
}

\author{
A. NACHAB ${ }^{\text {a }}$ \\ and NEMO collaboration \\ ${ }^{a}$ Centre d'Etudes Nucléaires de Bordeaux Gradignan \\ BP 120, Le Haut Vigneau, 33175 Gradignan Cedex (France)
}

\begin{abstract}
The first data of the NEMO 3 neutrinoless double beta decay experiment have shown that the radon can be a non negligible component of the background. In order to reduce the radon level in the gas mixture, it has been necessary first to cover the NEMO 3 detector with an airtight tent and then to install a radon-free air factory. With the use of sensitive radon detectors, the level of radon at the exit of the factory and inside the tent is continuously controlled. These radon levels are discussed within the NEMO 3 context.
\end{abstract}

Keywords: Double beta decay, NEMO, Rn, Electrostatic collection.

PACS: 23.40.-s, 29.40.-n

\section{INTRODUCTION}

The NEMO (Neutrino Ettore Majorana Observatory) experiment, now running in the LSM (Laboratoire Souterrain de Modane, depth of $4800 \mathrm{~m}$ w.e.), investigates the neutrinoless double beta decay ( $2 \beta 0 \mathrm{v})$ of various nuclei [1]. The observation of such a process will give us fundamental information's concerning neutrinos, i.e., their absolute mass scale and matter/antimatter symmetry.

NEMO 3 is a very low radioactive background detector. According to its origin, the background events can be divided into two categories. The first category is called internal background and has its origin inside the source foils. This component is mainly due to the presence of radioactive impurities in the foils and eventually to a surface radon deposition. Particularly dangerous are $\beta$ emitters with high $\mathrm{Q}_{\beta}$ values like ${ }^{208} \mathrm{Tl}\left(\mathrm{Q}_{\beta}=4.99 \mathrm{MeV}\right.$, ${ }^{232} \mathrm{Th}$ chain) and ${ }^{214} \mathrm{Bi}\left(\mathrm{Q}_{\beta}=3.27 \mathrm{MeV},{ }^{238} \mathrm{U}\right.$ chain and $\left.{ }^{222} \mathrm{Rn}\right)$. The second category of background is called external background and is caused by electrons or photons generated everywhere else except within the foils. One component of this background is due to radioactive isotopes present in the construction materials, as photomultiplier tubes, shielding, etc. This contribution was minimised by a strict selection of low radioactivity materials during the NEMO 3 construction [1]. Another component comes from the radon present in the air of the laboratory, but also from the radon emanation out of the rock, concrete, electronics components, etc...

In the LSM, the air is renewed two times per hour with fresh air from outside the mountain delivered through the tunnel ventilation system. The radon rate is extremely variable, depending on the period of the day and of the week, and is correlated to various parameters like the outside weather and the tunnel ventilation conditions. On the average it is around $15 \mathrm{~Bq} / \mathrm{m}^{3}$. The first data recorded with NEMO 3 and a fast measurement with a radon detector have shown that the NEMO gas contained around $15 \mathrm{mBq} / \mathrm{m}^{3}$ which gives about 8 events/year in $2 \beta 0 \mathrm{v}$ energy bin of the ${ }^{100}$ Mo source [2]. More detailed analyses have shown that the origin of this radon is due to leaks between sectors. Since this level of background was considered to be too high, a reduction by at least one order of magnitude was required. The chosen solution has been to cover the NEMO 3 detector with an airtight tent whose total volume is flushed with an air delivered by an anti-radon factory. For monitoring these installations two radon detectors with sensitivity in the $\mathrm{mBq} / \mathrm{m}^{3}$ range have been used.

In the following we will briefly describe the anti-radon device, the radon detector and we will give examples of the radon behaviors as a function of time both at the exit of the anti-radon factory and inside the NEMO 3 tent. 


\section{THE ANTI-RADON DEVICE}

In the beginning of 2003, the NEMO collaboration decided to build an airtight tent with a plastic film to fully enclose the whole detector including the electronics which is located just below the detector. Few days after its installation, we did not see, as expected, any reduction of the level of radon inside the tent. This was explained by a strong radon emanation from the electronics, and we had to separate the volume of the NEMO 3 detector from the electronics. Within such a situation the level of radon in the tent decreased by about a factor of 3 , around $5 \mathrm{~Bq} / \mathrm{m}^{3}$, clearly not enough. This has shown the need to flush the volume of the tent with a "radon free" air, and to build an anti-radon factory.

The principle of the radon trapping facility is shown in figure 1. It has been designed and built by our Czech collaborators, and tested in Prague before to be installed in the LMS in September 2004. Radon trapping is basically done as for other atoms or molecules by using a charcoal trapping under a temperature of $-50^{\circ} \mathrm{C}$. The specifications of this system are: compressor $(7$ bars $)$, filtration with oil separator $(0.03 \mu \mathrm{m})$ and dust separator $(0.1 \mu \mathrm{m})$, air dryer with a dew point $-70^{\circ} \mathrm{C}$ for 8.5 bars, cooling unit and two adsorption columns with internal diameter of $600 \mathrm{~mm}$ and $3 \mathrm{~m}$ high, each one loaded with $500 \mathrm{~kg}$ of charcoal (activated carbon K48 from Silicarbon Aktivkohle). As indicated in the right part of the figure 1, the radon-free air is sent to the upper part of the NEMO 3, with a typical flow of $150 \mathrm{~m}^{3} / \mathrm{h}$.
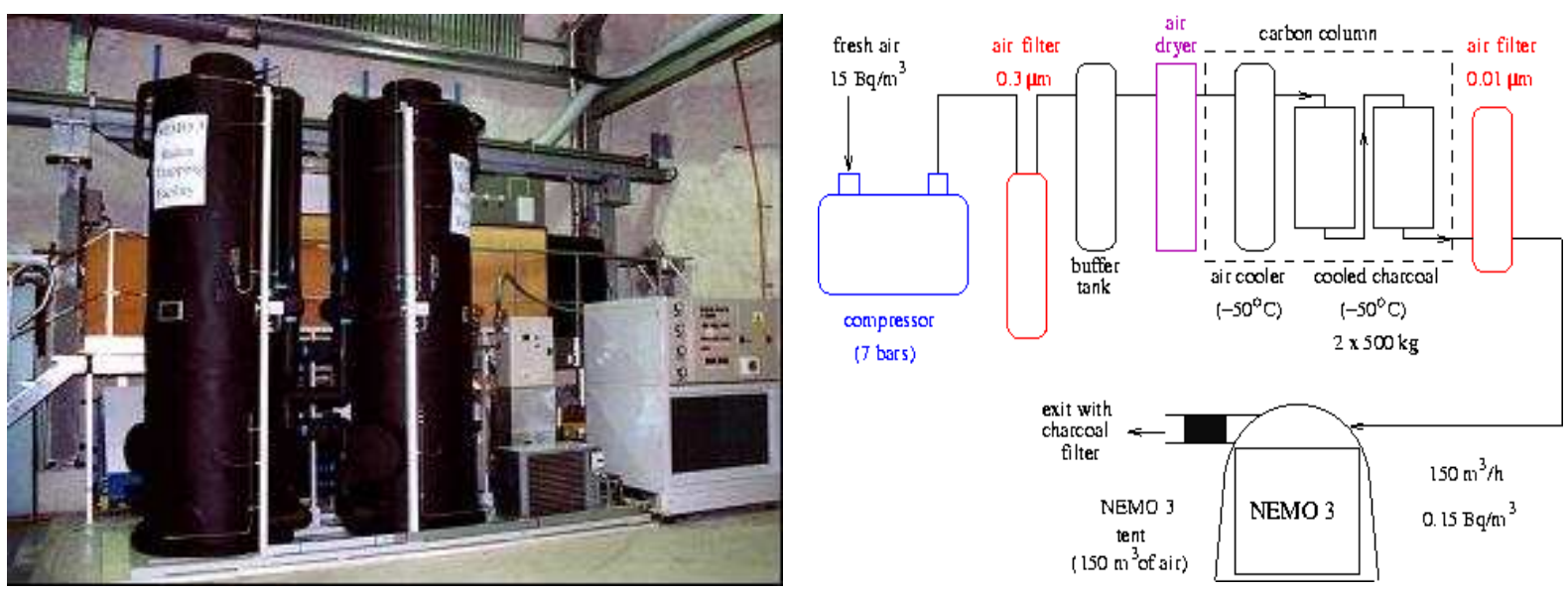

FIGURE 1: Principle of the radon trapping facility.

\section{RADON MEASUREMENTS}

\section{1- Radon Detector}

In order to measure and monitor the radon level within the NEMO 3 environment, two identical highsensitivity radon detectors were built by our Japanese collaborators with the same designed than those used for the SuperKamiokande experiment [3]. The principle of the radon detector is the electrostatic collection of the positively charge daughter nuclei of ${ }^{222} \mathrm{Rn}\left({ }^{218} \mathrm{Po}, \mathrm{E}_{\alpha}=6.0 \mathrm{MeV}\right.$ and $\left.{ }^{214} \mathrm{Po} \mathrm{E}_{\alpha}=7.7 \mathrm{MeV}\right)$ on the surface of a PIN photodiode. This diode is also used for the energy measurement of the emitted alpha particle. Figure 2 gives a schematic drawing of the radon detector. It consists of a cylindrical stainless steel vessel of 68.71 of volume, a PIN photodiode in the upper center, a high-voltage $(-1500 \mathrm{~V})$ between the vessel and the collector, an amplifier circuit and a feed through. In order to measure the radon activity, the ${ }^{214}$ Po peak $\left(E_{\alpha}=7.7 \mathrm{MeV}\right)$ is mainly used for the following reasons: firstly this alpha peak is rather pure and has a lower background, secondly the collection of the ${ }^{214} \mathrm{Po}$ has a much higher efficiency than the collection of the ${ }^{218} \mathrm{Po}\left(\mathrm{E}_{\alpha}=6 \mathrm{MeV}\right)$. This last effect is due to additional ionizations through the beta decay of the intermediate nuclei ${ }^{214} \mathrm{~Pb}$ and ${ }^{214} \mathrm{Bi}$. Note that if the gas entering the radon detector contains some impurities like water vapor or alcohol, the ${ }^{218}$ Po nuclei is quickly neutralized and its collection efficiency strongly reduced. As an example, for the NEMO 3 gas, composed of He with few \% ethyl alcohol, water and argon [1], the $6 \mathrm{MeV}^{218} \mathrm{Po}$ alpha peak is not seen at all, even after 1 week of data taking.

The typical sensitivity is $\sim 1 \mathrm{mBq} / \mathrm{m}^{3}$ corresponding to $1 \alpha$-event detected in $24 \mathrm{~h}$ in the ${ }^{214}$ Po peak. 


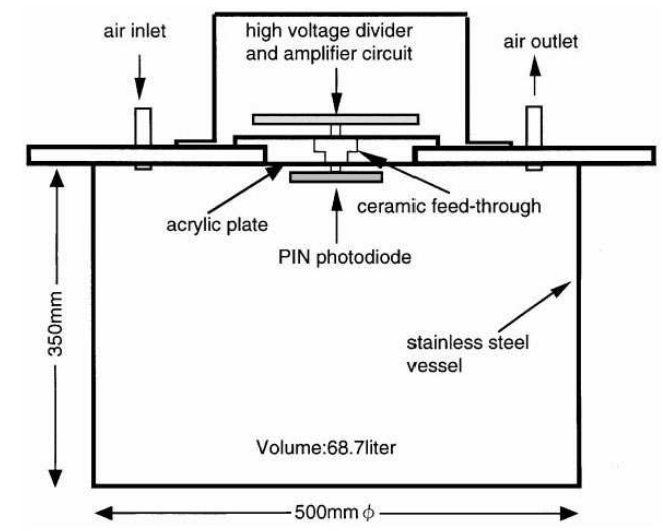

FIGURE 2: A schematic view of the high-sensitivity radon detector.

\section{2- Radon monitoring at the exit of the anti-radon factory}

In June 2005, after a traffic accident in the tunnel, the anti-radon facility was stopped during a few weeks. When we restarted, the collaboration decided to monitor the air at the exit of the facility. Figure 3 shows the evolution of the radon activity during about one year and half. One point corresponds to a $24 \mathrm{~h}$ measurement. In this period we had several short stops due to different events (power shut-down, maintenance, etc...). We note that after each stop the counting rate comes back to the low level rather fast, within one or two days. During the first 15 days, the counting rate of the $7.7 \mathrm{MeV} \alpha$-peak was around the background rate of the used radon detector ( $\sim 5.8$ counts/day). Then, it increased until a maximum of 30 counts/day, followed during about 150 days by a regular and slow decrease. After about one year, the radon rate started again to increase. Until now, this behavior is not fully understood; we suspect effects of saturation in the charcoal column or may be some detection problem like very small leaks between the air-facility and the radon detector. On the average the amount of radon in the air delivered by this device is $18 \mathrm{mBq} / \mathrm{m}^{3}$, which corresponds to a reduction by a factor 1000 compared to the ambient air of the LSM.

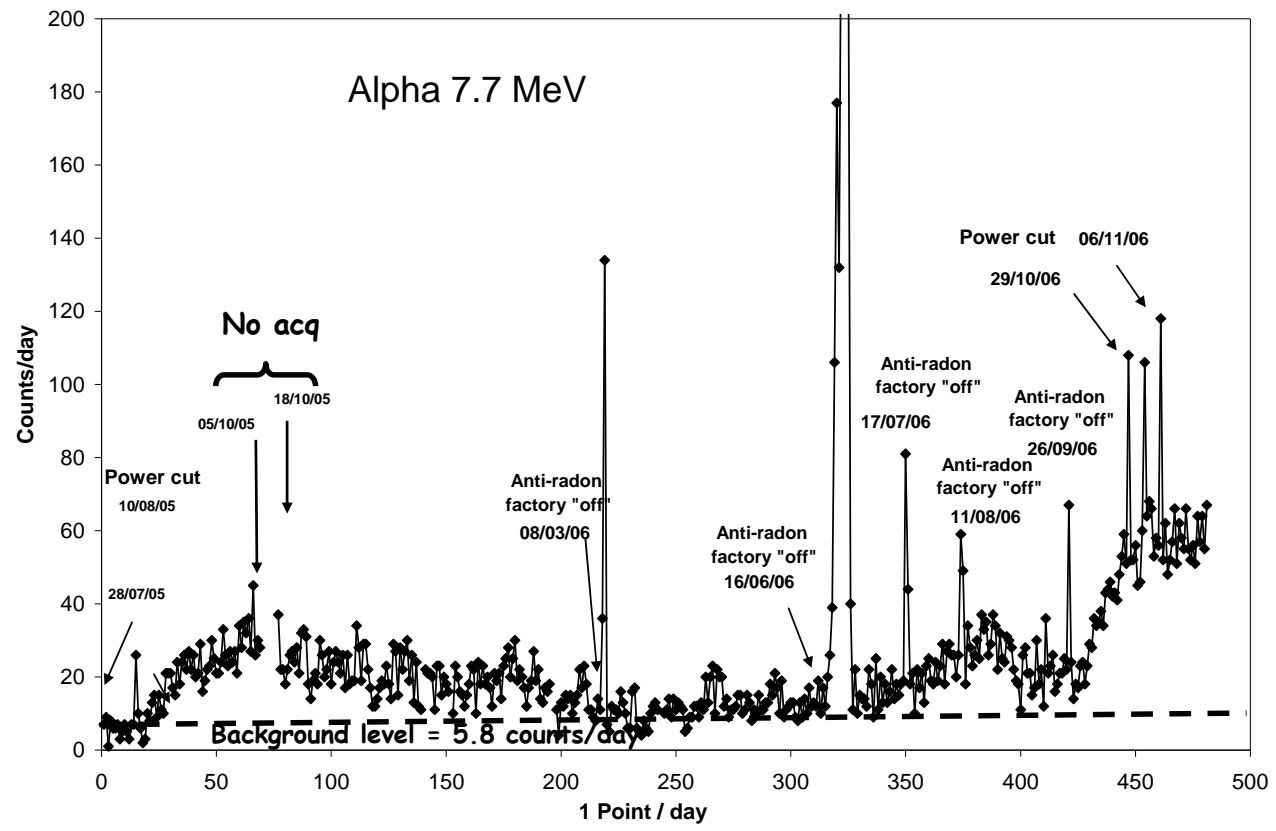

FIGURE 3: Radon level at the exit of the anti-radon factory.

\section{3- Radon monitoring in the NEMO tent}

As already said, the air delivered by the factory is sent directly inside the NEMO 3 tent with a flow of 150 $\mathrm{m}^{3} / \mathrm{h}$. With a second detector, the level of radon in the tent is also continuously monitored. Figure 4 gives the 
data between January $11^{\text {th }}, 2006$ to September $13^{\text {th }}, 2006$. One point in curve corresponds to a $6 \mathrm{~h}$ measurement. As before, during this period of time, there have been several stops due to different events (energy calibration of NEMO 3, electrical shut-downs, etc...). And we can note also that after few hours the radon level comes back to the initial value. The average radon activity in the tent is $170 \mathrm{mBq} / \mathrm{m}^{3}$. The difference between the radon activity in the delivered air and the radon level in the tent is explained by the emanation from the glass and voltage dividers of the photomultiplier tubes of the NEMO 3 electronics and also some leaks in the tent.

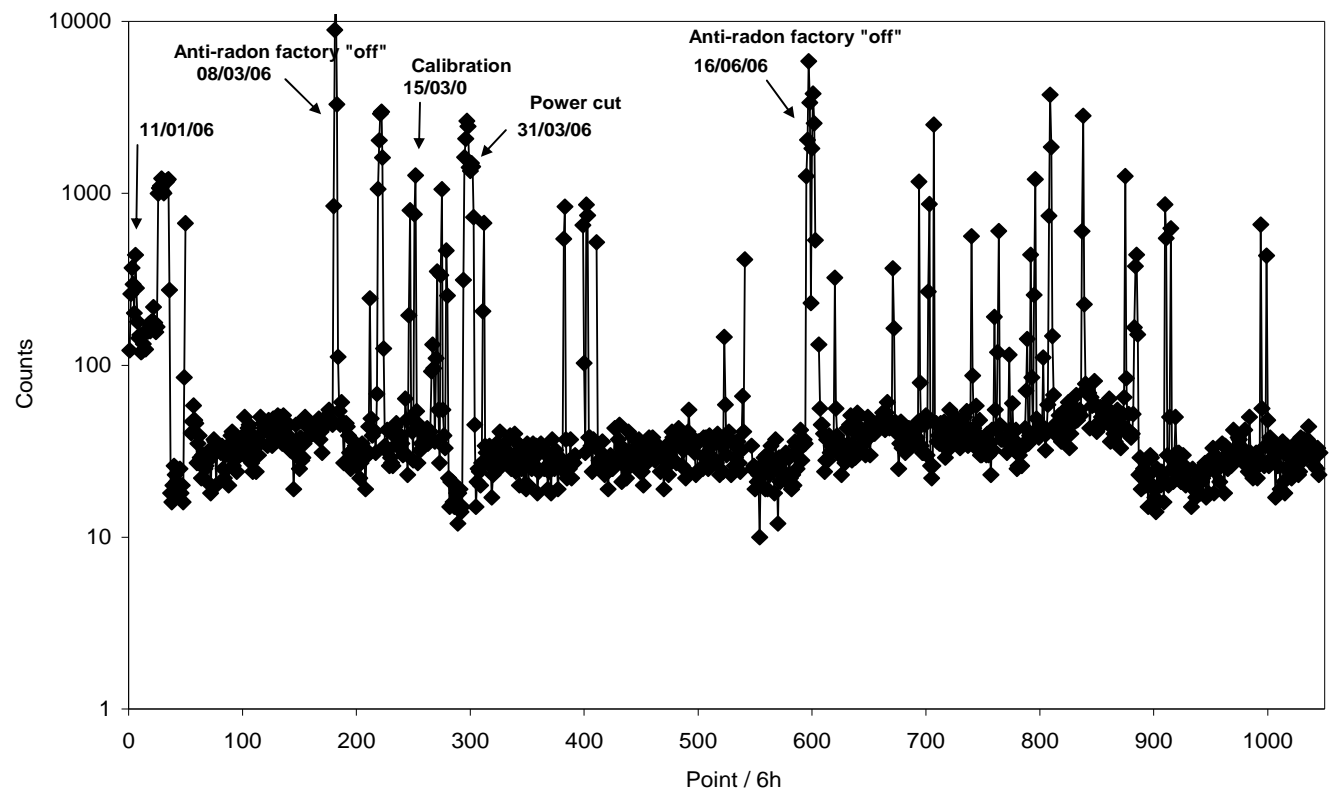

FIGURE 4: Radon level inside the NEMO tent.

Note that the radon level of the NEMO 3 gas cannot be monitored directly with the radon detector because of the alcohol contained in the gas. After few days of running there is an alcohol deposition on the surface of the PIN photodiode, which induces a very high noise in the $\alpha$-spectrum.

\section{CONCLUSION}

The radon trapping facility is in operation in the LSM since October 2004 and together with a tent, it allows a reduction factor around the NEMO 3 detector of 2 orders of magnitude, from $15 \mathrm{~Bq} / \mathrm{m}^{3}$ down to $170 \mathrm{mBq} / \mathrm{m}^{3}$. When the NEMO 3 gas, at the exit of the NEMO 3 detector, is flushed through a radon detector, we measured a radon activity around $1-2 \mathrm{mBq} / \mathrm{m}^{3}$. This level is quite satisfactory since it represents less than 1 event/year in $2 \beta 0 \mathrm{v}$ energy bin of the ${ }^{100} \mathrm{Mo}$. However it should be pointed out that with a factor 100 reduction in the tent, we observed only a factor 10 reduction in the NEMO 3 gas. This result can be explained if we admit the existence of a small radon source inside the NEMO 3 volume. Such hypothesis is reinforced by the fact that during the radon measurement, we observed also a few alpha counts at $8.8 \mathrm{MeV}$, corresponding to a ${ }^{220} \mathrm{Rn}$ (thoron) peak. We planned to study more these weak radon and thoron components with a new detector.

Finally, the radon monitoring is useful for the data analysis: any event candidate to the $2 \beta 0 \mathrm{v}$ decay should not be correlated to a high radon level.

\section{ACKNOWLEDGEMENTS}

The author would like to thank the LSM staff for their technical assistance.

\section{REFERENCES}

[1]: R. Arnold et al, Nucl. Instr. and Meth. A 536 (2005) 79.

[2]: X. Sarazin et al, Nucl. Phys. (Proc. Suppl.) B 143 (2005) 221.

[3]: Y. Takeuchi et al, Nucl. Instr. and Meth. A 412 (1999) 334. 